\title{
To Think Human out of the Machine Paradigm: Homo Ex Machina
}

\author{
Alaric Kohler \\ Published online: 29 January 2010 \\ (C) Springer Science+Business Media, LLC 2010
}

\begin{abstract}
This article attempts to show that the metaphorical conception of human being as a machine takes a very specific epistemological standpoint. To make short the complex task of considering the implication of this paradigm for psychological and behavioral sciences, three important mismatches between the machine and the living human will be considered. Experience, agency and plasticity of human being are excluded in the scientific models and research activities when they are situated in the machine paradigm. For this reason, I claim that the machine paradigm does not offer the relevant frame for integrating results from various domains or approaches within human sciences, even if it can sometimes produce relevant scientific knowledge in certain domain at the scale of detailed investigation. Due to the importance of overcoming the fragmentation of scientific knowledge to solve the crisis in psychology, an "organic paradigm" should be elaborated which provides a new epistemological framework.
\end{abstract}

Keywords Paradigm $\cdot$ Causality $\cdot$ Machine $\cdot$ Crisis in psychology $\cdot$ Epistemology

Metaphor

\section{Introduction}

The great success of Newton mechanics in physical science struck the collective consciousness very deeply, notably because of the massive change it brought into daily life through the first industrial revolution of the 18th century. Not only the fundamental organization of society changed, but more particularly to our concern the apparition of all different kinds of machines and devices in the following centuries has been in itself a critical time for human thought. We know that the artefacts available in a culture do not only change practices and practical

\footnotetext{
A. Kohler $(\bowtie)$

Institute of Psychology and Education, University of Neuchâtel, Espace L. Agassiz 1, 2001

Neuchâtel, Switzerland

e-mail: alaric.kohler@unine.ch
} 
intelligence, but also our verbal intelligence and thus our representations, since Vygotsky pointed out the fundamental linkage between practical intelligence and the development of sign or symbolic operations (Vygotsky and Luria 1999). The possibilities opened by the early physics and related sciences dramatically increased the efficiency of human action upon the physical environment. The first aircrafts based on thermodynamics or the discovery of electricity proved to be very impressive evidence of the growing sciences, to name only those among many examples.

To recall this major turning point in western history is important, because it can be understood as the psychological trigger of a specific conception of science. This conception of science carries high expectations on the utility and objective character of scientific knowledge, and is based on the simplistic formal models corresponding to the early stage of scientific knowledge existing at the time (Bertalanffy 1968). The amazing applications of Newtonian physics and related theories established the success not only of the empirical method but also of mathematical expressions of knowledge. Antiques philosophers were already searching geometrical expressions of the knowledge about nature, in order to achieve criteria of beauty. With Newton physics, the quest for a mathematical knowledge about nature takes a new dimension, building on systematic empirical investigations and the powerful tools of mathematics at disposal. Nevertheless, this new conception of natural sciences is deeply embodied in the cultural setting of the time, which includes very different aspects such as the demarcation from religion through a systematic demystification of nature, the strong belief in the potential of formal system to represent reality, and in the power of engineering to lift humans life's conditions.

This conception of science still endures nowadays, and has become the main social representation about science. Social representations are very resistant to change, and can easily survive over centuries with nothing more than shallow or peripheral changes (Moscovici and Hewstone 1990). In addition, new generations largely inherit these social representations of science through school education (Driver et al. 1996). This has important consequences for the understanding of the crisis in psychology, which is still deeply inhabited by this conception of science or its implications, as some authors have clearly demonstrated (see e.g. Marková 2008). From sociology of science we know that not only the general population as a whole shares social representations, but also scholars set their thinking and scientific work within the frame of the same representations. This is even more profound when these representations are from a different scientific domain than their own (e.g.Jost 1992; Latour 2000).

\section{Mechanisms and Causality in Psychology}

Recurrent references to "mechanisms" in psychology provide an example of the way this conception of science frame the scientific thinking, even more relevantly that the mere concept of "mechanism" is very rarely defined or even investigated on an epistemological level. Yet, "mechanism" has been used so much in different contexts in scientific models that eventually scholars might take the concept without committing themselves to the mechanical conception. Another illustration of this underlying presence of the mechanic conception is the broad use of simple causality 
in human sciences, a concept which has been dropped by most natural sciences long ago, as Russell addressed the point to philosophers in 1913:

"The law of causality, I believe, like much that passes muster among philosophers, is a relic of a bygone age, surviving, like the monarchy, only because it is erroneously supposed to do no harm." (Russel 1913, p. 1)

More interestingly, while the physics paradigm changed in the early 20th century, human sciences have adopted the mechanist view, using the machine as a main metaphor to represent human activities and functioning, so that it became later the main stream approach in psychology. Nevertheless, psychology at its beginning entailed different approaches standing on an epistemological ground of their own, as Psychoanalysis and Gestalt psychology. Unfortunately, these approaches never reached integration with other domains of human sciences or with other theoretical approaches strongly influenced by the meachanist view (e.g. Behaviorism). Rather, they were left aside when a totally new kind of machine brought back the original amazement of the first "psychological shock", and all its hopes: the computer. The computer progressively captured the attention of scientists in both human and cognitive sciences so much that the machine not only became the mainstream metaphor but a paradigm of scientific investigation, in the sense of a reference frame for the community of researcher in the domain (Kuhn 1962). Most scholars set their investigation within this frame of mind, consciously or not. By now many have forgotten that computers are after all a man-made inert object and everything this mere fact implies on an epistemological level. Most of these implications were well known by the Artificial Intelligence theoretical initiators (e.g. Turing 1950), and in their project of designing machines matching human cognitive functioning it brought the opportunity to stimulate philosophy with very difficult questions, as for example:

"How are observations to be used to get knowledge about the world, and how are the other kinds of knowledge to be obtained? In particular, what kinds of knowledge about the system's own state of mind are to be provided for?" (McCarthy and Hayes 1969, p. 465).

The development of cybernetics into the theory system, starting from the claim that the methods for studying living organisms and machines "are at present similar" (Rosenblueth et al. 1943), to the critical turning point of the General System Theory of Bertalanffy (1968), shows clearly the constant concern and the theoretical failure of converging both machines and living organism in a single model. Indeed, Bertalanffy demonstrates the severe limitations in studying humans as a machine or computer though the distinction between closed systems typical of the early physics or machine design, and open systems which are entitled to represent living organisms. The further development of this stream interestingly meets the concept of dynamical systems in physics, and other non-reductive approaches of complexity that cannot be discussed here without entering in too many details.

\section{There is a Machine Paradigm}

The existence of a "machine paradigm" underlying scientific methods and theories in psychological, cognitive and behavioral sciences needs to be considered seriously. 
This paradigm is most often implicit, and it is not rare even to find bits and pieces of its epistemological framework in the alternative approaches themselves, which explicitly claim not to be mechanical. This last point is not so surprising when we take into consideration how social representations can frame scholars' thinking, as said earlier in this paper.

My point is to critically examine why the machine paradigm in general does not allow integration of psychological and behavioral sciences. Following the idea that the crisis in psychology is a real problem related to "underlying philosophical tensions" (Goertzen 2009), I propose to critically examine the epistemological influence of deterministic mechanics, which led to a similar fragmentation in the history of science, failing in its endeavor to unify all domains of science and philosophy.

However, an acceptable argument for the use of the computer metaphor in cognitive science is to argue that metaphors are useful tools for thinking complexity, and intentionally using the computer as an explicit metaphor is a correct way of making science. Whichever position one chooses about the use of metaphors in science, the epistemological inadequacy of the machine paradigm for unifying psychological, cognitive and behavioral sciences should be a point of agreement, and explicitly recognized. The result of this critical process should not forbid the usage of the machine metaphor, but rather increase the awareness of its limits. One can call a train "iron horse" in order to successfully explain its function (travel, transport of goods, etc.), as Native Americans used to do when the train first appeared in their land, but it is much better to also know the limit of the comparison to avoid feeding the train with straw and giving it a rest at night.

The problematic issues are situated at the epistemological level, which is a reason for being much more an obstacle for the elaboration of a relevant theory fitting the data, rather than for producing data or locally explain them. It might even not be problematic in certain cases when it is only about having a singular study of a specific question. Nevertheless, if we take seriously the last advance in scientific epistemology, we must be aware that facts do not give themselves to the researcher like mere objects of perception (Bruner and Goodman 1947), but are recognized according to values and norms. More generally, it is now a common knowledge in philosophy of science that empirical work is theory driven (Hanson 1958). Therefore, the empirical results established within a paradigm must at the least be reinterpreted when this paradigm is replaced by a new one, and it probably would appear much better in many cases to carry new research to critically examine the past results.

\section{The Limits of the Machine Paradigm}

We need to consider at a very general level the epistemological problems in considering a living human being within the machine paradigm in psychology and related sciences. My contribution here is only to stress three points of the machine paradigm that hinder the integration of knowledge from different domains in psychological and behavioral science. For each issue presented, some suggestions about the requirement for a more advanced epistemological framework will be 
provided, in order to prepare the move towards an organic paradigm, with which a human being can be investigated as genuinely alive and in which different traditions and approaches can be embedded. This contribution to a new paradigm follows an interpretation of the current crisis in psychology according to Kuhn's understanding that psychology is pre-pragmatic (Yurevich 2009, p. 94).

"Paradigm" is used here in the sense of Yurevich catalogs of "cognitive systems in psychology" (Yurevich 2009, p. 92), however my point of concern only aims at commenting the "upper linkage" of psychological theories. If what I suggest to be a "machine paradigm" shares much of the "natural scientific paradigm" Yurevich identifies, I would not hold they are one and the same. Indeed, one can choose for a much more contemporary paradigm inspired of natural sciences or its related philosophical and methodological roots, and nevertheless escape the mechanical conception of natural sciences and machines. Moreover, an approach fitting a natural scientific paradigm in biology taking into account the complex processes through which organism and its environment mutually adapt could very well fit into an organic paradigm as well. What is crucial to our discussion is not the methodology used or the object of study, but is both the a priori definition of the objects of study which frame the authorized scientific program and the nature of the determination considered as a satisfying explanation or model. In the machine paradigm, the area under study is limited by the metaphor of the machine or computer, and the determination is thought of as a deterministic causality. The natural scientific paradigm as Yurevich describes it can have several different kinds of determination, some mechanical, some not. However, standing in the domain studying human beings, we do not only need to specify the limits of the machine paradigm compared to the biological dimension, but also compared to the cultural and symbolic activity more specific to humans, which Vygotksy names "higher psychological functions".

"Organic" therefore does not indicate the human being is considered for his biological properties only, but refers to the easily observable fact that humans are alive and therefore made of organic matter. Two main ideas of the Greek roots of the word "organic" are under consideration here: First, the idea of lifeblood found in the

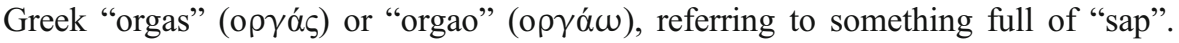
The sap is a very inspiring concept in the antique philosophy, and is often referred to as the force of life itself, animating the nature. The second idea is found in the same

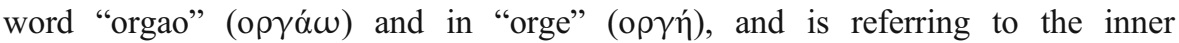
uneasiness, the way we feel or think, or to any feeling moving the soul like anger and passion. It is the core idea about having an inner life. Besides, the word "organon" itself means the instrument for labour or music, and is related to the root "erg" $(\varepsilon \rho \gamma)$ which refers to work and labour. Using this word in medical science to designate the parts of the body realizing a certain function - a certain work - in a merely biological sense, reveals the premises of the metaphor of the machine as it is considering the body as an instrument of the soul. This distinction between living and inert entities is the starting point of the following critique of the machine paradigm, and is grounding the idea that it might require a radically different epistemological framework to study humans than it does to explain a machine.

During the analysis, I will keep in mind human beings rather than animals in general, even if considering the animal life would probably be sufficient for stating the limits of the machine paradigm. This precision is important as the mismatches 
between the machine paradigm and the human are even more striking when one considers the higher psychological functions. Nevertheless, an organic paradigm should be entitled to bridge together approaches only interested in biological properties and functioning, like neuropsychology, and other approaches only interested in higher psychological functions. The philosophical question of the identity of the mind with the brain is intentionally left aside in this paper: as there is no clear evidence for either thesis about this difficult problem, I assume that both positions can be taken within the same paradigm if we agree on what should be explained to make models about organisms relevant. Moreover, this is also a way to avoid being tied up with the traditional Western world dichotomies, among which body and soul are one of the most famous pair.

\section{The Crucial Issue of Experiencing}

The most obvious mismatch between a machine and a living being relates to experience or, in other terms, to the subject's point of view. The ignorance of this existential dimension of human life has been the strongest critique against the use of the machine metaphor since its beginning. It was the main reason for Phenomenology to set up a new epistemology in a field largely occupied by models fitting the machine paradigm, of which the positivist standpoint is the most famous. By "existential dimension" of human life, I mean the life as the individual experiences it. It does not only refer to memory or stored perceptions, but also to the stream of thoughts, feelings, narrative shapes, and anything else possibly describing the psychological dimension as a first person lives it.

In philosophy of science, intentional and normative properties of action are often taken for the basic features giving account of experience as a human specificity:

"Underlying most of the arguments for a radical distinction in methods of enquiry in the natural and the human sciences lay two features of human behaviour which have no counterpart in the behaviour of inorganic materials. Human behaviour display or seems to display intentionality, that is human actions are what they are by virtue of their meaning, point or aim. And human behaviour also displays normativity, that is it is generally subject to appraisal as correct, proper, appropriate or as incorrect, improper, inappropriate." (Harré 1998, p. 33)

Considering that for behaviors to display intentionality or normativity a subject must perceive this behavior at a certain point, I suggest here-mostly for simplification - that personal experience and existential dimension are rooted in perception: there is no experiencer without a perceiver. A living being has his own way of experiencing the world, while the machine does not perceive events in its own way, so that the machine's own point of view (the emic dimension) and the machine's observer's point of view (the ethic dimension) can be confused into a single one without raising an epistemological issue: the knowledge produced is about the same object. More radically, one can also simply consider that a machine does not have a "point of view" at all, which ends to the same conclusion considering the limitations of the machine paradigm.

Whether a machine has perceptions or not, and even whether a machine could be designed that has all perceptions a human being has, or at least that such a machine 
is theoretically possible can be debated. In any case, even if one decides to call "perception" what a machine can sense of the environment around it, I suggest here to differentiate it from "experiential perception". Even if human perception would be only automatic, the specificity of the organic being still remain in the awareness he or she has of what perception a particular environment or event makes him or her have.

It is this awareness that gives us the feeling to be alive, being the very first process of our being-in-the-world. A child cutting herself with scissors for the first time can learn that the knife cuts, and if she does, it is through the awareness she has that the knife has hurt her. In addition, this experience of cutting provides her with a perception of herself, or said differently as her body being linked to herself through the awareness she has of the perception the knife gave her by touching her body in a specific way. It is also this awareness which renders possible (most often unconsciously) to adapt our perception to our previous experiences, and hence to become amazingly efficient for selecting and proceeding our own perceptions about the environment. Human beings accomplish this task in a very different way machines (would) do, using the relevance of information from an individual point of view and to a certain extent from decision making heuristics (see for instance the work of Gigerenzer and Todd 1999), or even according to "the way we feel at the moment", and not from systematic and analytical preset procedures. Procedures set by the programmer will not evolve, or only evolves according to the programmed algorithms, but never according to the machine's "choice" or own regulation of interest. Most known is the consequence of this point that the machine cannot learn or transform itself without external intervention. I suggest here that it is also because it has no awareness of its own perceptions, about which reasoning can be constructed.

Consequently, an organic paradigm should include the possibility for knowledge from both subjective and objective perspectives, the first being about the experiential perception of individual and the processes grounded on it (meaning-making, communication, learning, etc.), the second being about the physical and behavioral characteristic of human being as they can be seen from several others (physical reflex, performance, attitudes, conformity, etc.). More importantly, as serious scientific researchers in human sciences we should be able to link one with the other. A good example of such an attempt is the concept of "enaction" introduced by Varela in Neurophenomenology to link the neurobiological processes with the first person own experience (Flores-González 2009, p. 192).

This integration would not be so difficult — after all we experience it everyday-if most of the theory were not in a paradigm that would not allow us to think other links between subjectivity and objectivity than a mere correspondence between the two, or even a confusion of the two when the second is the unilateral cause of the first. However the history of psychology is not my first concern in this paper, it stands to reason that the disappearance of the experiential dimension from scientific agenda of psychology is not merely due to the machine paradigm, but also comes from the passionate methodological debate leading to the exclusion of introspection as a scientific practice and later to the denial of the inner psychological life by several approaches, among which the Behaviorism has probably been the most influential. 


\section{Agency}

The passiveness of machines is a nice comfort for a scientific paradigm: a machine only reacts and never does something out of nowhere, and - even better-it reacts always the same way to a given input, at least if it functions normally and does not need reparation. Maybe it is necessary to specify that this passiveness also includes computers, even if their complexity can make them look like they have activity of their own through a feed-back regulation. Action and agency are words widely used, but not always with a full understanding of the epistemological consequences. If agency is taken only in the sense of a reaction to stimuli, even when stimuli is understood in the broad sense of the whole cultural, social and physical environment, what is considered is de facto passiveness, understood as an antonym of agency, or some kind of "ability to react". The recent crisis in experimental methodology about the amazing difference observed when little details of the experimental setting are changed, or even just the experimenter in person, provides good evidence of the active role subjects play interpreting the environment given to them (Balez 2008). Moreover, it has been demonstrated long ago that the experimenter intervenes in his research and in a way creates the reality he or she is looking at, which can lead to the mere confirmation of the researcher's theoretical expectations independently of the experimental setting, a methodological bias known as the "Pygmalion effect" (Rosenthal and Jacobson 1968).

Agency, in an organic paradigm stepping over this pitfall, should allow space for action considered as creation. Through meaning making processes, a human is creating the situation - at least to a certain extent. I am not claiming that all behavior of living being is an action in this strict sense, but rather that this genuine action is possible, and is performed more or less often. In an organic paradigm, one should leave open the possibility for the living being to act or function cognitively merely due to his/her individual subjective life, conscious or not. Such an action or process is not fully predictable from an external point of view, neither from any knowledge taking only the objective perspective.

This is about the well-known problem of scientific model set within the machine paradigm where $20-30 \%$ of the sample does not match the prediction of statistical analysis. An organic paradigm should take this state of affairs seriously, as a fundamental characteristic of living beings, rather than treating it as a methodological problem or even as an unachieved state of science than ideally should reach a point where there are no such outstanding results, just like in the Newtonian conception of physics it was taken for granted - probably as an heritage of Greek philosophers - that the laws of motion were to have an exact mathematical expression, and if possible through an elegant equation. In this frame of mind, a data not quite matching the equation is due to lack of precision in measurement. This way of proceeding led early physics to great success and I have no intention to criticize it here, but to argue that it is not adapted for knowledge about living beings. Even in physics, it was not more than a useful approximation overcome by Relativity Theory. In an organic paradigm, inexactitude of formal models should be considered as the result of genuine activity, the "margin of freedom", rather than the physics' concept of "margin of error". It is not to say than humans always or constantly are unpredictable, for the empirical tradition in Human sciences show many regularities, and indeed there are many behaviors of 
humans that seems automatic. However, the mere fact it is possible they do so, disfavors a deterministic model as it ought to be in the machine paradigm. In brief, the organic paradigm should provide all scientific models with this margin of freedom, even if it is in the minimal sense of having a probability of "creativeness" that outstand the model prediction or explanation. To get to know the size of this margin better in different settings of human activities and context can become thereafter a very interesting topic of research.

\section{Determinism}

If subjectivity is considered irrelevant and agency replaced by a predictable reactivity in the machine paradigm, it is above all to save the philosophical tenet of a deterministic world, fully knowledgeable and predictable with a suppositional accomplished science. This is the core of the conception of science inherited from the 17th century I referred to in the introduction of this paper. The Newtonian mechanics takes place within a strong philosophical system, where the machine gained so much importance that even metaphysics represented the world as a huge clock (which was at the time the most complex machine, just like our computers today), and God as a craftsman... The tricky question wherever God himself was behaving in a predictable way and therefore fitting in a determinism world stayed ever unsolved, and merit our attention here as it stresses the temptation scientific enterprise fell into: making human the programmed machines that can be comfortably studied like clocks, but of which the design still requires an agency that has been denied to humans, and that is consequently attributed to a God remaining out of the range of empirical science research (at least at this time).

The most important consequence of the determinism embodied in the machine paradigm for psychology and behavioral sciences is the expectation of finding causes of all phenomena considered as needing explanation (which is more or less arbitrary in itself, as one usually does not question what he/she considers obvious). In addition, these causes must have the characteristic of the deterministic physics : they cause the effect with an unalterable necessity and they can be clearly identified in the environment through analysis in the literal sense of "decomposing the object of study in small components". This expectation can be more simply explained at a daily life level: if a car brakes down, one can be certain that there is somewhere in the car something - a piece of mechanics or, more likely in the 21 st century, of electronics - that is broken or altered in its functioning and can be therefore considered as the deterministic cause of the brake down. If this component is replaced, the car works again. In addition, this defective element can be found with a process of analysis that lead the researcher to the place where a hole stands: first testing a whole pipe, and then half of it, etc. It works for repairing a car, because the car is a machine. But for an organic being, where we assume that the whole definitely has properties that parts have not and is an open system that can develop new actions, and which is made of components which themselves can change functioning over time autonomously, both analytical and necessity expectations are irrelevant. Marc Jeannerod writes, not less than 30 years ago:

"Superior mental functions assembled in such terms as Intelligence, Consciousness, Will, etc. could thus represent emerging properties of a 
psychophysiological whole assuming the relations with the environment. Generally, emerging properties of a whole cannot we deduced from the functioning of the different parts of this whole (for instance the emerging property of DNA cannot be deduced from the biochemical composition of the molecule), but remain in an interdependency with the whole." (Richelle and Seron 1980, p. 201)

The spread of determinism in psychology merits in more in-depth exposition than I can give here. Also, several authors have made precise and systematic demonstrations of particular aspects of this critical issue, which I am only pointing out. For example, Rom Harré writes in his "message for psychologists":

"Psychologists have long used the concept of "attitude" as an enduring mental state that is causally implicated in the genesis of actions. Philosophers, with an interest in psychology, have offered the belief-desire pair as the basic format for the explanation of what people do. This leads to the idea of a mental mechanism that is activated in appropriate circumstances. It should be clear by now that it is a mistake to use a cause-effect schema for studying the relation between expressed intentions and people's intended actions." (Harré and Tissaw 2005, p. 239)

Following the same reasoning as for agency on the function of awareness, an organic paradigm should only include models free from this determinism, in order to avoid excluding a very important feature of human life from inquiry. These models escape a determinist issue if they are allowing an individual to change himself over time, or leaving a possibility for a self-regulated evolution of living beings in a sense that experiential perception and all processes grounded on it (e.g. meaning making, learning, etc.) are able to intervene with the course of development. It is to allow determination both to the subjective and objective process. Again, I do not argue than every individual uses this possibility, neither that it is constantly used. Nevertheless, the possibility for living human beings to change themselves with efficiency is fundamental for an organic paradigm, and probably the main point of difference between inert and alive entities. An organic being must be considered having at least the plasticity his key components have. "Plasticity" is indicated here because the brain plasticity is the closest concept describing this possibility of living beings to act towards what they will be. Wallon used the same word in order to point out the active role humans take in their own development:

"Both imitation and representation are developed, in opposition with modifying reactions from the milieu which directly follow from external excitations and appetites, as a plastic ability of shaping (in French "façonner" T.N.) oneself on the model of things..." (Wallon 1942, p.125-126, translation by the author)

Nevertheless other terms have tried to capture this aspect of human life among authors. From a Kantian moral philosophy, one could name it "autonomy" in the literal sense of the ability of human to set a law for him or herself. This "law" corresponding to the specific set of rules governing (probably partially) the reactions and actions of the individual in a way he/she changes him/herself to a certain way. 
Interestingly, the evolution theory respects this plastic dimension-at least potentially - as species produce all sorts of variations through individual evolutions, and the selective process decisive of the ones to survive among all possibilities only comes in a second phase: it is to say that there is not genetic determinism or whatever programmed evolution that can account for all changes of living beings, it is rather a space of freedom where individuals in interaction with their milieu change this or that way (and for many in an ill adapted way), before the surviving comes into play to keep some of the creative change and discard others.

This autonomy can be both intentional and conscious or not. If a fish changes for a better fit to its environment, this self-regulation feels very different for the fish than it does for a human being, deciding for example to focus his conscious thought process on a specific type of religious information making him a believer, or to join a political group changing his/her view on the government. Nevertheless, in any of those cases, the individual might acquire a new way of thinking, different behaviors, and new skills. To avoid any misunderstanding in this delicate issue, it is necessary to stress here that there is a counterpart to self-regulated or self-made change which plays the most part in human life: habitude. Through addiction to chemical substance ingested in or even produced by the organism (adrenaline or emotional trigger), or simply through the comforting experience provided by the repetition, humans most of the time do not use the possibility of changing themselves, but merely repeat the same patterns of thought or behavior. The distinction between lower and higher psychological function might also be important here. However, habitude is taking nothing away from the possibility to make change that no inert object has. It is within this potential of plasticity that narrative can explain so much of human behavioral and psychological functioning.

\section{Working Towards an Organic Paradigm}

\section{A Necessity for Integrating Psychological and Behavioral Sciences}

The machine paradigm makes integration of the various approaches of psychology and behavioral sciences problematic on all the three points considered. Firstly, it discards all domains of psychology taking the perspective of the subject from investigation because experiential perception is not considered. Secondly, a model elaborated within this paradigm becomes unable to explain agency. Finally, the deterministic endeavor of the machine paradigm exclude the mere possibility for human beings to take an effective part in his own development as a person, and therefore cast out of science any approach of human activity and functioning accepting some indetermination or selfdetermination as a use of freedom (the "free will").

An organic paradigm extending the frame of scientific investigation to the three points risen above would in principle solves one of the problems Yurevich stresses in his analysis of the crisis in psychology (Yurevich 2009), the fragmentation of the scientific knowledge. My claim is that a large part of responsibility of this problem lay in the (ab)use of the metaphor of the machine to model human activities and functioning. Indeed, the machine paradigm is incompletely referring to human 
activities and functioning and therefore does not provide a framework where every approach finds its own place within a global scientific plan.

The organic paradigm should also be a good guide for collaborative scientific work as Zittoun et al suggest (Zittoun et al. 2009), allowing each approach to bring specific contributions within the paradigm in a complementary way instead of leading to competition or methodological debates. Indeed, if it is about finding the right cause or chain of necessary determination, there is place for only one "mechanism" to be true. To the contrary, in an open system different findings from different approaches and perspectives can complement themselves without competing, raising the level of complexity on an informative way. However, the tools for thinking the precise interactions or relationships of the complementarities within the organic paradigm are yet to be invented. This issue is discussed later in the paper. Last but not least, this new paradigm should match all requirements of scientificity, for instance fit Popperian criteria of scientificity (Doria 2009) or others.

\section{Can a Simulation be a Scientific Model?}

The new products of Artificial Intelligence (AI) for the toy market (for instance : Ugobe life forms, www.pleoworld.com) precisely stresses the three missing points I have discussed in this article, in order to convince their audience that the little cuddly robotic toys look like real living creatures : the robot moves apparently from his own initiative (an imitation of agency), it seemingly experiences feelings and emotions (an imitation of having an experiential perception), and it's personality changes over time (an imitation of individual plasticity, notably taking some of the interactive environment in a way that makes the individual able to escape a predictable deterministic evolution). However, a scientific model cannot be content imitating these characteristics of the living, it needs to represent them, which is far more demanding and does not allow it to simply reproduce the visible effects (as the robot does in this case) without giving at least an explicit theory which can be falsified of the underlying processes in the organic system, if direct empirical investigation is not possible.

All attempts to use the word "agency" within the machine paradigm and to interpret data about it will eventually be no more than a artificial reproduction, just like the computer can be programmed on such a complex way that it looks like it is doing something of its own (switching off after a certain time of inactivity, or more recently offering all kinds of suggestion in reaction to the user's actions), while in reality this is only differed or conditionally programmed reactions. Even recent AI trials to produce intentional robots are explicitly referring to a method of mimicking observed human behavior or functioning (Kozma 2008). Moreover, the reductionism of human action into a deterministic behavior following a set program was explicitly chosen by AI initiators for creating an intelligent machine, and was not a naïve confusion:

“The problem of 'free will' assumes an acute but concrete form. Namely, in common-sense reasoning, a person often decides what to do by evaluating the results of the different actions he can do. An intelligent program must use this same process, but using an exact formal sense of can, must be able to show 
that it has these alternatives without denying that it is a deterministic machine."

(McCarthy and Hayes 1969, p. 468).

A simulation is not a scientific model when it comes to represent human being, because the experiential perception is a priori excluded and even more so the other two points raised here. A simulation for meteorological processes allowing us to make weather forecast is of different epistemological nature: the forecast given by the simulation and the weather itself are one and the same thing when it is exact. Supposing we have an exact prediction of a human behavior given by a simulation, this will not represent the whole reality of human action, if it is just performing physical movement without entailing a phenomenological experience. All individual living organisms are making sense of the situation they are involved in within their specific personal narrative and history. This is likely to lead to a plastic change of their self, and there is a certain probability that the simulation which worked once or hundred times with efficiency to predict this behaviour will not be right the next time, because a totally unexpected and outstanding decision has been taken. Therefore, when it comes to imitate the visible aspects of human activities and functioning, one cannot seriously maintain that the imitation exhausts the phenomenon. The theorists of AI are very aware of this state of affairs, and for several decades they have been trying to overcome this fundamental limit by using organic cells for the future machines!

\section{First Building Stones of the New Paradigm}

I will end this article by giving a few suggestion of what could be taken as the first building stones of the organic paradigm, and indicate their usefulness for empirical research. The three issues examined above are to be considered as the main features of an organic paradigm. Any scientific model or theory pretending to explain or refer to human beings that cannot address all these three issue is somehow limited and probably under the influence of considering human beings as machines.

For example, concerning the first issue, a model needs to account for the experiential dimension of the human subjects. It does not mean that every research has to study also this dimension, but rather that in the theoretical model elaborated to explain empirical data, a specific and appropriate place must be given to the first person experience. The experiential dimension does not only include consciousness, as it encompasses all processes (conscious or unconscious) and perceptions an individual human being can have of his own. Most of these perceptions remain completely unconscious, but can be the focus point of one's mind in given circumstances or feed inner process of thinking like the interpretation of an event happening several years later. For example, if someone is moved by a strong anger, the way he/she feels his/her anger taking over the control of his/her behavior cannot be confounded with the way anger makes him/her behave and look from an observer point of view, and even a very elaborate description from this external point of view in a biological way, for instance explaining the complex actions of hormones in the body, is unable to refer to the perception of the angry person. Knowledge about both dimensions are useful for different purpose: if it is about training the individual person to master his/her anger, a theory about hormones will be meaningless as the 
person can use psychological knowledge only when it is related to what his/her perception are. In this case, it is knowledge from the experiential dimension that can be used and directly related to the world as the individual living human being knows it. To the contrary, if the purpose of the knowledge is to create a medication balancing the mood changes, the experiential dimension is not firstly useful at all, and it is an external and biological precise understanding that is needed.

Still, there is another very important aspect that must be examined further. I have considered earlier in the paper that the limitation of the machine paradigm is twofold: both the domain of scientific investigation was limited by the metaphor of the machine, and the conception of the causality by the mechanic and deterministic assumption. Including experiential dimension of human life, human agency and the plasticity of human development considerably broadens up the field of investigation and this in itself helps integration of different approaches in psychology and behavioral sciences. Yet, the mechanic causality must also be replaced by a more appropriate relation of determination in an organic paradigm. For this crucial issue, several candidates might be relevant.

Rather than relations of causality between a preceding cause and a subsequent effect, I suggest to consider relations within the organic paradigm as relations of creation. Humans do not cause effect, but rather create effect. A link of determination as creation is radically different: the creation is not always identical under the same conditions, and what has been created cannot be fully explained by one past event, or neither by a group of past events summed up by an automatic computation. I suggest to consider humans as the creators of psychological reality (at an individual level, social reality at an intersubjective level, sociological reality at a group level, and anthropological reality at a cultural level, etc.).

What is created not only follows from the past state of the world, but can be partly determined in order to an imagined future, or even just remain in ambivalence (Abbey and Valsiner 2005). This creation does not only relate the agent to the action he or she is performing, but lays at the core of the psychological reality through the meaning making process in perception itself. Interpreting a behavior of someone else, understanding a word with normative connotations, or even making sense of the function of an artefact is creating a psychological reality. The product of the creation is likely to differ from individuals to individuals, and is partly due to the irreducible decision of the agent (at least in some cases), but it is nevertheless intertwined with external influences from the environment, yet not in a deterministic causal way.

Considering the system made of human action and experiential perception as open (i.e. not fully determined or not fully defined) is of crucial importance, because human action and experience are not fully predictable from the past, neither are they always fully defined at the present time. Indeed, possibly the human is acting upon anticipation, which is his strategic decision of manifesting a certain power on the world in order to achieve an aim or intention. The imagined future state of affairs cannot be taken as some sort of final cause of the action in a classical deterministic way, since this state of affairs does not exist yet, and might well never do. Moreover, such actions made in anticipation of an imagined future state of affairs are both determined by the intention, and by the meaning system of the agent, because it is not only intentional but also attributing meaning to the consequences of the action in such a way that provides a reason for achieving it. 
In an interdisciplinary conference about scientific explanation (Richelle and Seron 1980), Francis Jacques suggests to solve the opposition between explaining a behavior with a cause, and understanding it with the meaning of experience. The solution comes from G. H. von Wright's works, and consists in complementing the deterministic approach of classical science with a strategic approach specific to human science, which is referring to model of decision rather than mechanical model, and which is providing justification for action with a different type of determination than determinism.

"Causal explanations apply to the relation between facts (literally "things done/ made" T.N.) and consequences. We are grounded to introduce in the system an irreducible part of human intervention." (Richelle and Seron 1980, p. 105, translated by the author).

Introducing human decision as an intervention in the world takes a great importance for overcoming the misleading mechanics, as Jacques states:

"Yet the epistemologist can wish better than overcoming the antithesis of motive and cause, he can wish trying to extirpate the determinist illusion itself, which claims the sufficiency and uniqueness of causal explanation. To do so, one should: $1^{\circ}$ ground the contiguity of explanatory approaches. $2^{\circ}$ ruin on the philosophical level the pretention of mechanical models to reduce human action." (Richelle and Seron 1980, p.104).

Jacques is explicitly working towards an alternative to the causal determination. His suggestion is to establish two separate worlds, one of causes and the other of reasons, with a point where the experience of action and its cause combines. This point is at the very moment we experience our efficiency on things. Moreover, in a human development the action as an intervention on the world is primitive to the inferences about causes and effects in the world of objects:

"It is that the notion of action as intervention is conceptually antecedent to the notion of cause. (...) It is the agent's intervention in the knowing of things which serves as a model to the idea of producing effects. (...) When he submits a law to the proof of experience, in doing so the experimentation makes something happen. The process of verification of laws includes the use of his power." (Richelle and Seron 1980, p.106, translated by the author).

The agent is not only acting in a deterministic world of objects, but intervenes in a world in creation. When a human acts, or intervenes in Jacques's vocabulary, using agency after a decision or choice grounded on this unique experiential perception belonging to the subject, the human being creates something in the world of living.

\section{Creation: A Dialectic Determination?}

Creation relates resources for creativity (see for instance the work of Zittoun et al. 2003 ) with the created. It is not a relation totally free of constraints, and it has some specific forms of determination, which brings some stability in the world of creation. This stability is nevertheless much more flexible than the one of deterministic causeeffect chains, and corresponds much better to what we experience as someone's personality. Interestingly enough, psychology failed in the attempt to empirically 
account for the stability of personality within the machine paradigm, using only deterministic relations between variables. If personality eventually appeared a myth, contradicting our everyday life experience, it is probably because the epistemological relation between an agent and his actions is misled in the machine paradigm. Personality, consciousness, and other awkward issues in psychology can find a totally new sense and relevance if humans are considered as creators of psychological reality.

Human development is another good example of a phenomenon that a process of creation explains better than any causality-based research. The search for an appropriate model of development has led several of the main figures in early psychology to use the dialectic developed by Hegel and originated in Kant's work in philosophy of knowledge. The Marxist tradition applied the abstract and unspecified concept of dialectic to social sciences with a certain success. Vygotsky (Van der Veer and Valsiner 1994) refers to Freud's attempt to find a unifying explanation of human development as a dialectic between the biological and social:

"So, according to Freud, the history of the human psyche embodies two tendencies, the conservative-biological and the progressive-sociological. It is from these factors that the whole dialectic of the organism is composed and they are responsible for the distinctive 'spiral' development of a human being." (pp. 16-17)

Wallon, a excellent French psychologist largely ignored for his Marxist political views (Jalley 2006), made a very interesting developmental psychology based on the dialectic between the affective and cognitive motives of human being. The dialectic offers him a model where different tendencies struggle and determine together an outcome in an open-ended way, starting a movement through a tension that needs a resolution through a creative dynamic. Piaget also used the dialectic instead of causal models, to make intelligible the dynamic between the activity of the subject and the object in the cognitive development, and explain the process through which knowledge about the objective world is possible. Piaget and Inhelder (1963) reminds us one of the main claim of Marx's sociology, which is to consider that the action of mankind on nature is for production. He draws a link with his own findings in psychology of knowing, writing that we only know objects by acting upon them, producing some kind of transformation. Production and transformation are somehow creations. However, the dialectic is only rarely explicitly addressed in Piaget's work, except for a posthumous book that remains a first trial in the domain (Piaget 1980).

Eventually, the challenge for an organic paradigm is to be able to take in consideration the both beliefs reported by Moscovici as "a miracle which is not finishing to surprise us" (Moscovici and Hewstone 1990, p.564): the belief of ancient societies in the power of the thought to shape reality, and the belief grounding the modern and classical scientific approach in the power of object to inform the thought and determine its evolution and content. And the authors conclude:

"We have to suppose that each express on its own ways some truth about the link between our inner world and our outer world." (Moscovici and Hewstone 1990, p.564)

I believe that the dialectic is a good candidate to successfully take up this challenge within an organic paradigm. 
Vygotsky's study of the role of imagination and creativity (Van der Veer and Valsiner 1994) in the development makes a promise starting point for the understanding of creation. His detailed analysis of how fantasy relates to concrete thinking, thinking in concepts and desire brings highlights about the fundamental role creativity plays in human development, and later in the adult life. In addition, he discusses empirical results showing that creativity is playing different roles in childhood, adolescence and adult life. Therefore, it might very well be that beyond few general principles of creation the particular biological and cultural developments of individuals offer important variations in the way human beings create.

These few considerations, which I cannot extend here without starting a very long study, simply show than theoretical efforts exist in the past of psychology and have been successfully explaining complex human behavior above the limits imposed by a mechanical paradigm. It is from this first body of work that a stream of research in psychological and behavioral sciences can be developed within an organic paradigm, in a way that permit the integration of different approaches for a real scientific debate about fundamental questions.

Empirical research of certain domains where the object of study entails the most challenging complexity (learning, language, cognitive development, etc.) has already been driven towards considering human being as a creator. To give only a few illustrations, the concept of "meaning making" shedding light on the interpretative nature of mankind (i.e. Bruner 1996), the socio-constructivism (i.e. Perret-Clermont 1979) explaining how learning emerges from social interaction, or the emergentist theories in psychology (for a review see Sawyer 2005), are all on their own way stepping out of the machine paradigm to explain human as a creator of his activity and cognitive world, at the crossroad of experiencing and behaving.

In addition to the specificity of the relation of creation, all properties of the psychological reality must be seriously considered (intention, norms, etc), as several scholars have already started doing. For instance, Rom Harré sets an ontology of speech acts instead of things and events (Harré and Tissaw 2005), drawing implications from Wittgenstein's philosophy for a more advanced paradigm in psychology. Brinkmann (2009) claims for a fundamental normativity in social life, considering the distinction between facts and value a naturalistic fallacy. These approaches given as examples could very well find a common roof in the organic paradigm, defining more precisely what the objects of the psychological reality are.

\section{Conclusion}

There is an enduring conception of science inspired by the machine metaphor. This conception can be misleading because the models elaborated by the scholars within this paradigm carry expectations about the nature of knowledge that mismatch their object of study, i.e. human being. In addition, the machine paradigm lies on principle which have not been proven reliable through empirical research, neither have they been theoretically demonstrated, since natural sciences themselves have adapted the deterministic metaphysics. Many scholars explicitly disagree with these expectations or the global deterministic philosophy at the source of the machine paradigm, but 
still use this theoretical framework and its related concepts unconsciously, and are therefore tied up with its epistemological constraints.

For the integration of human sciences into a paradigm of their own, a new epistemological framework needs to be built which entails at the least three important characteristics: the organic paradigm must include the first person experiential dimension, agency and plasticity in the sense developed in this paper.

In addition, the new paradigm should consider human beings as potentially and effectively creating meaning, structure (relational, narrative, interpretative, conceptual, ...), intention, situations, etc. when performing an action or event just making sense of his or her environment. Several existing approaches bringing important empirical findings and new concepts in psychological and behavioral sciences can easily combine into an integrated model of human activity and cognition within this organic paradigm. Philosophical work describing the psychological reality in terms of value, norms, intention, meaning, etc. can also integrate the same model providing an ontology of the complex reality in which human minds carry their lives. A further analysis of the determination through creation, using the dialectic developed in the Marxist materialism or other forms, can provide the organic paradigm with theoretical tools for understanding how the various powers at stake in human life are participating in the creation of the psychological reality. Therefore, the paradox of the poet given by Vygotsky (Abbey and Valsiner 2005) will appear a most common act of creation:

"When the poet says: "I will dissolve in tears over this fiction" he realizes that this figment is something unreal, but his tears belong to the realm of reality." (p.284)

\section{References}

Abbey, E., \& Valsiner, J. (2005). Emergence of Meanings Through Ambivalence. Forum Qualitative Sozialforschung / Forum: Qualitative Social Research, 6(1), Art. 23.

Balez, R. (2008). Pygmalion au laboratoire. Contribution à la modélisation de l'influence implicite des attentes théoriques de l'expérimentateur sur les participants. Paris X Nanterre.

von Bertalanffy, L. (1968). General system theory. New York: George Braziller.

Brinkmann, S. (2009). Facts, values, and the naturalistic fallacy in psychology. New Ideas in Psychology, $27,1-17$.

Bruner, J. S. (1996). Frames for thinking: Ways of making meaning. In D.-R. Olson \& N. Torrance (Eds.), Modes of thought: Exploration in culture and cognition (pp. 93-105). New York: Cambridge University Press.

Bruner, J. S., \& Goodman, C. C. (1947). Value and need as organizing factors in perception. Journal of Abnormal and Social Psychology, 42, 33-44.

Doria, N. G. (2009). No more than conjectures: Popper and the ethics of scientific entreprise. Integrative Psychological and Behavioral Science, 43(1), 116-125.

Driver, R., Leach, J., Millar, R., \& Scott, P. (1996). Young people’s images of science. Buckingham: Open University Press.

Flores-González, L. M. (2009). Phenomenological views on intersujectivity: towards a reinterpretation of consciousness. Integrative Psychological and Behavioral Science, 42(2), 187-193.

Gigerenzer, G., \& Todd, P. M. (Eds.). (1999). Simple heuristics that make us smart. New York: Oxford University Press.

Goertzen, J. R. (2009). On the possibility of unification: the reality and nature of the crisis in psychology. Theory \& Psychology, 18(6), 829-852. 
Hanson, N. R. (1958). Patterns of discovery: an inquiry into the conceptual foundations of science. Cambridge: Cambridge University Press.

Harré, R. (Ed.). (1998). The singular self: an introduction to the psychology of personhood. London: Sage.

Harré, R., \& Tissaw, M. A. (Eds.). (2005). Wittgenstein and psychology: a practical guide. Aldershot: Ashgate.

Jalley, E. (2006). Wallon et Piaget: Pour une critique de la psychologie contemporaine. Paris: L'Harmattan.

Jost, J. T. (1992). Social representations and the philosophy of science: belief in ontological realism as objectivation. Ongoing Production on Social Representations - Productions Vives sur les Représentations Sociales, 1(2-3), 116-124.

Kozma, R. (2008). Intentional systems: review of neurodynamics, modeling, and robotics implementation. Physics of Life Reviews, 5(1), 1-21.

Kuhn, T. S. (1962). The structure of scientific revolutions. Chicago: The University Chicago Press.

Latour, B. (2000). When thing strike back: a possible contribution of science studies'to the social sciences. Britisch Journal of Sociology, 51(1), 107-123.

Marková, I. (2008). The epistemological significance of the theory of social representations. Journal for the Theory of social Behaviour, 38(4), 461-487.

McCarthy, J., \& Hayes, P. J. (1969). Some philosophical problems from the standpoint of artificial intelligence. In B. Meltzer \& D. Michie (Eds.), Machine intelligence (Vol. 4, pp. 463-502). Edinburgh: Edinburgh University Press.

Moscovici, S., \& Hewstone, M. (1990). De la science au sens commun. In S. Moscovici (Ed.), Psychologie sociale (pp. 539-566). Paris: PUF.

Perret-Clermont, A.-N. (1979). La construction de l'intelligence dans l'interaction sociale. Berne: Peter Lang.

Piaget, J. (Ed.). (1980). Les formes élémentaires de la dialectique. Saint-Amand: Gallimard.

Piaget, J., \& Inhelder, B. (1963). Les opérations intellectuelles et leur développement. In P. Fraisse \& J. Piaget (Eds.), Traité de psychologie expérimentale (Vol. 7, pp. 109-155). Paris: PUF.

Richelle, M., \& Seron, X. (Eds.). (1980). L'explication en psychologie. Paris: Presses universitaires de France.

Rosenblueth, A., Wiener, N., \& Bigelow, J. (1943). Behavior, purpose and teleology. Philosophy of Science, 10(1), 18-24.

Rosenthal, R., \& Jacobson, L. (1968). Pygmalion in the classroom: Teacher expectation and pupils' intellectual development. New York: Holt, Rinehart \& Winston.

Russel, B. (1913). On the notion of cause. Proceedings of the Aristotelian Society, 13, 1-26.

Sawyer, R. K. (2005). Social emergence: Societies as complex systems. Cambridge: Cambridge University Press.

Turing, A. M. (1950). Computing machinery and intelligence. Mind, 59(236), 433-460.

Van der Veer, R., \& Valsiner, J. (Eds.). (1994). The Vygotksy reader. London: Wiley-Blackwell.

Vygotsky, L., \& Luria, A. (1999). Tool and symbol in child development. In R. Van der Veer \& J. Valsiner (Eds.), The Vygotsky reader (pp. 99-174). Cambridge: Cambridge University Press.

Wallon, H. (1942). De l'acte à la pensée. Paris: Flammarion.

Yurevich, A. V. (2009). Cognitive frames in psychology: demarcations and ruptures. Integrative Psychological and Behavioral Science, 43(1), 89-103.

Zittoun, T., Duveen, G., Gillespie, A., Ivinson, G., \& Psaltis, C. (2003). The use of symbolic resources in developmental transitions. Culture and Psychology, 9(4), 415-448.

Zittoun, T., Gillespie, A., \& Cornish, F. (2009). Fragmentation or differentiation: questioning the crisis in psychology. Integrative Psychological and Behavioral Science, 43(2), 104-115.

Alaric Kohler graduated in Philosophy from the University of Neuchatel in 2004, and in Social Psychology from the University of Geneva 2 years later. His PhD research is situated in Educational Psychology, and focus on teaching Newtonian physics to college students. In this work, the learning difficulties in science education are related to epistemological problems, causality in scientific explanations, and misunderstanding in classroom social interactions. 